\title{
МЕТОДОЛОГИЯ “ВОРОНКИ ПРИЧИННОСТИ” КАК ПРОМЕЖУТОЧНЫЙ СИНТЕЗ “СТРУКТУРЫ И АГЕНТА” В АНАЛИЗЕ ДЕМОКРАТИЧЕСКИХ ТРАНЗИТОВ
}

\author{
А.Ю. Мельвиль \\ Мельвиль Андрей Юрьевич, доктор философских наук, профессор, декан факультета политологии, \\ проректор МГИМО (У).
}

Несколько лет тому назад я попробовал использовать методологию “воронки причинности” для анализа структурных и процедурных факторов демократических транзитов [см. Мельвиль 1998, 1999]. Моя логика была примерно следующей.

Более или менее четкая причинность, удовлетворительно и комплексно объясняющая феномен демократического транзита и зарождения демократии в целом (будь то ее “органическое прорастание”, “силовое внедрение изнутри” или такое же “навязывание извне”), в имеющейся на сегодня литературе не прослеживается. Рождение каждой новой демократии остается во многом загадкой. При построении общих моделей генезиса демократии одни авторы делают упор на структурные факторы (прежде всего на государство- и нациообразующие, социально-экономические и культурно-ценностные), а другие — на факторы процедурные, особенно на выбор и последовательность конкретных решений и действий тех политических акторов, от которых зависит процесс демократизации. Иными словами, транзитологическая литература фактически воспроизводит и по-своему интерпретирует уже вполне традиционную для социальных наук дилемму “структуры и агента (актора)” [см., напр. Giddens 1984; Archer 1990; Hay 1995; Wendt 1987 и мн. др.], в рамках которой источником каузальной детерминации различных социальных явлений признаются либо “объективные” общественные структуры, либо “субъективные” действия тех или иных акторов (индивидов, групп, государств).

Сторонников первого подхода [см. Lipset 1959; Almond, Verba 1963; Rustow 1966; Inglehart 1977 и др.] интересуют прежде всего эмпирически выявленные и зафиксированные общие корреляции между некоторыми социально-экономическими и культурно-ценностными переменными и вероятностью установления и сохранения демократических режимов в конкретных странах. При этом данные корреляции понимаются именно как структурные (т.е. обусловленные влиянием неких объективных общественных структур, а не субъективными намерениями и действиями акторов - участников политического процесса) условия демократизации и демократии. Выделяются (если взять обобщенную модель) четыре основных типа структурных предпосылок демократии: во-первых, обретение национального единства и соответствующей идентичности; во-вторых, достижение относительно высокого уровня экономического развития; в-третьих, распространение культурных норм и ценностей, предполагающих признание демократических принципов, доверие к ключевым политическим институтам, межличностное доверие, чувство гражданственности и т.д.; в-четвертых, наличие эффективного государства и действенного властного аппарата. Анализ показывает, что такие корреляции (если отвлечься от некоторых исключений) действительно существуют. Другое дело, что они не равнозначны предварительным структурным условиям, без которых невозможно запустить процесс демократического транзита. Прежде всего, установленные корреляции указывают не на некий императив, а лишь на факторы, благоприятствующие демократизации либо затрудняющие ее. Кроме того, то, что иной раз принимают за предпосылки и условия демократии, в реальности может оказаться (и нередко оказывается) результатами самого процесса демократизации.

В частности, практика демократических транзитов третьей волны показала, что обвал недемократических режимов и попытки построения новых (как правило, заимствованных) демократических институтов и практик напрямую не связаны и тем более не предполагают в обязательном порядке наличия и массового распространения в переходном обществе каких-либо специфических структурных (иначе говоря, “объективных") обстоятельств. Начиная с середины 1970-х годов демократические транзиты имели по большей части эндогенный характер и были — особенно на начальных стадиях — преимущественно результатом определенных решений и выбора политических тактик и стратегий ключевыми (а их обычно не 
слишком много) политическими акторами, хотя общество в целом, разумеется, создавало этому процессу тот или иной фон.

В фокусе внимания приверженцев второго подхода [см. O’Donnell, Shmitter, Whitehead 1986; Di Palma 1990; Przeworski 1991; Karl, Shmitter 1991; Linz, Stepan 1996 и мн. др.] находятся не экзогенные, а собственно эндогенные факторы демократизации и демократии — различные конкретные процессы, процедуры и политические решения, осуществляемые самими агентами демократизации. При таком угле зрения последовательность и взаимообусловленность политических решений и действий, выбор тактик теми акторами, которые инициируют и осуществляют демократизацию, оказываются важнее для ее исхода, нежели существующие (или отсутствующие) к нужному моменту предпосылки демократии. Главное при данном подходе - взаимодействие конкурирующих элит, сознательный выбор ими в процессе политического торга и соперничества организационных форм и институтов политического устройства.

Поборники этого - процедурного - подхода исходят из того, что никакие “объективные” социальные, экономические, культурные и иные факторы не в состоянии ни объяснить, ни предсказать, кто конкретно, какие политические силы и акторы, когда и при каких обстоятельствах будут отстаивать недемократический статус-кво или бороться за его ниспровержение. Они считают, что действия политических акторов, инициирующих и осуществляющих демократический транзит, не определены их “объективным” положением в общественной структуре. Напротив, их “субъективный” выбор сам творит новые политические возможности.

В компаративистской литературе по транзитологии и политическим изменениям в целом эти два методологических подхода довольно резко противопоставлены, однако у меня сложилось впечатление, что в действительности между ними нет непреодолимого противоречия. Более того, они взаимодополнимы, ибо фактически делают упор на разные стороны единой группы явлений. Теоретически ничто, по крайней мере а priori, не препятствует попытке синтезировать две методологии, одна из которых обращает внимание на структурные факторы демократии и демократизации (пусть даже их универсальность сомнительна), а другая - на процедурные.

Очевидно, что многие ключевые моменты конкретных решений и действий политических акторов обуславливают ход демократического транзита и соответствующих общественных преобразований. Акторы сами выбирают свои стратегии и тактики, тем самым определяя специфику устанавливаемых процедур и институтов. Вместе с тем акторы осуществляют выбор политических институтов и действий в обстоятельствах, которые созданы не ими и являются внешними по отношению к самому выбору. Иными словами, этот выбор принимается отнюдь не в условиях общественной tabula rasa, на которой можно “нарисовать” любой политический проект. На него влияют не только сами процедуры, т.е. конкретные политические действия, но и структурные факторы, связанные прежде всего с культурными традициями и широким социально-экономическим контекстом. В самом деле, приступить к построению демократии можно не дожидаясь, пока созреют благоприятствующие ей условия, но исход конкретного демократического транзита и перспективы консолидации демократии в конечном счете зависят и от структурных - т.е. нацио- и государствообразующих, социально-экономических и культурно-ценностных — факторов. Ведь демократия как институционализированная неопределенность предполагает выбор между вариантами, которые сами уже в значительной мере определены. При этом именно структурные факторы определяют содержательное наполнение выбираемых формальных процедур и институтов (и объясняют, в частности, почему в одних случаях электоральные процедуры становятся важнейшим инструментом консолидирующейся демократии, а в других оказываются лишь “дымовой завесой” над имитацией демократии).

Исходя из высказанных выше соображений, я предположил, что попытка теоретико-методологического синтеза структурного и процедурного подходов к демократическим транзитам не только допустима в принципе, но и желательна, поскольку позволила бы учитывать более широкую совокупность факторов и переменных и строить более многомерные модели изучаемых процессов. Отправной точкой к такого рода предварительному (и промежуточному) синтезу могла бы стать, на мой взгляд, методология анализа, впервые использованная в классической работе Д.Кэмпбелла и его коллег “Американский избиратель” [Campbell et al. 1960] и названная ими “воронкой причинности” (funnel of causality). Справедливости ради должен сказать, что в самом общем и схематичном виде мысль о возможности использования методологии “воронки причинности” при анализе демократических транзитов была подсказана мне в частном разговоре норвежским компаративистом С.Ларсеном еще в 1997 г. Позднее упоминание об этой методологии в данном 
контексте я обнаружил в рукописной работе Дж.Мэхони и Р.Снайдера “Переосмысливая структуру и агента в изучении режимных изменений” [Mahony, Snyder 1995], которая в 2000 г. была опубликована в сборнике “Вызовы теорий демократии: размышления о направлениях в транзитологии” под редакцией С.Ларсена [Larsen 2000].

Применительно к анализу демократических транзитов использование методологии “воронки причинности” предполагало бы осуществление полифакторного исследования, последовательно сужающего фокус внимания от макро- до микроуровней. В соответствии с этой теоретико-методологической моделью, переменные, влияющие на ход демократического транзита (от первичной либерализации режима вплоть до учреждения новых демократических институтов и процедур), могли бы рассматриваться на следующих условных уровнях (от наиболее широкого макроуровня до максимально суженного микроуровня):

- внешняя международная среда (международная экономическая ситуация, политико-стратегические условия и отношения, межгосударственные и международные неправительственные взаимодействия, общемировой “дух времени” — глобальный Zeitgeist);

— государство- и нациообразующие факторы (единая территория, единое государство, чувство национальной идентичности и т.п.);

— общий уровень социально-экономического развития и модернизации, “современности” общества;

- социально-классовые процессы и условия (степень социальной дифференциации и развития, взаимоотношения между классами и социальными группами);

— социокультурные и ценностные факторы, доминирующие в обществе культурно-политические ценности и ориентации;

— политические (per se) факторы и процессы (взаимодействие партий, общественно-политических движений и организованных групп с новыми политическими институтами, выбор политических стратегий и тактик);

— индивидуальные, личностные политико-психологические факторы (конкретные решения и действия ключевых политических акторов).

В идеале постепенное продвижение в ходе анализа от переменных макроуровня к переменным микроуровня должно осуществляться в соответствии с определенной методологической логикой: спуск на каждый последующий уровень анализа предполагает, что объяснительный потенциал факторов предшествующего уровня уже исчерпан (а само явление так и осталось не до конца объясненным). Собственно говоря, в этом сужении фокуса анализа и заключается сама методологическая идея “воронки причинности”. Вместе с тем опускание с макро- на микроуровень как раз и предполагает постепенный переход от преимущественно структурного к преимущественно процедурному анализу. Таким образом, открывается путь для синтеза двух подходов в рамках общей методологической модели, которая в конечном счете может вывести на полифакторное объяснение того, как и почему происходят (либо не происходят) учреждение новой демократии и ее последующая консолидация.

В развитие указанного методологического подхода я попробовал дать эскиз возможной стратегии анализа структурных и процедурных факторов, в частности, в российском демократическом транзите: от международных макрофакторов (которые не были решающими) - к распаду советской государственности и возникновению кризиса национальной идентичности - далее к социально-экономическому контексту советского распада и российского транзита — затем к социально-классовым обстоятельствам (социальная база демократизации) и к факторам культурно-ценностным - а потом к собственно процедурному микроуровню: от выбора политических стратегий и тактик преобразований, взаимодействия политических сил вплоть до индивидуально-личностных особенностей ключевых политических акторов.

Увы, в силу разных причин эта исследовательская задача осталась незавершенной. Очень интересная альтернативная исследовательская линия была предложена В.Я.Гельманом [Гельман 2001], который, основываясь на широкой эмпирической базе, предположил, что обстоятельства и тип учреждаемых новых политических институтов в значительной мере определяют направленность и исход демократического транзита. Однако, насколько я понимаю, данная исследовательская линия пока остается скорее 
аналитическим вектором и еще не развернута в интегрированную теорию. Наконец, попытка риторического “снятия” самой транзитологической проблематики была предпринята Б.Г.Капустиным [Капустин 2001].

В этой связи возникает целый ряд вопросов и прежде всего вопрос о том, является ли методология “воронки причинности” оптимальной хотя бы в качестве первого этапа к созданию отсутствующей в настоящее время интегративной теории демократических транзитов (и политических изменений в целом). Разумеется, эта методология не лишена недостатков. Но, во-первых, идеальных методологий вообще не существует, а во-вторых, по крайней мере некоторые из высказываемых в ее адрес критических замечаний не во всем убедительны. Так, мне кажется не вполне обоснованным утверждение упоминавшихся выше Дж.Мэхони и Р.Снайдера, что она фактически изолирует акторов и структурные факторы друг от друга. Напротив, продвижение к конусу “воронки”, на мой взгляд, показывает, что акторы, выбирающие те или иные процедуры и действия, в очень многом как раз не свободны, не независимы от внешних (по отношению к ним) структур. Именно поэтому применение методологии “воронки причинности” (естественно, с учетом ряда уточнений) при исследовании демократических транзитов представляется полностью оправданным.

Нужно спросить себя и о другом: будет ли такое систематизированное и структурированное (в идеале) описание факторов объяснением самого явления? Безусловно, нет. Использование методологии “воронки причинности” при анализе демократических транзитов (и не только их) не может заменить поиска и разработки интегративной теории. Но это дело будущего.

Конечно, все сказанное выше не исключает возможности (и даже эвристической эффективности) специализированного изучения какого-либо из уровней “воронки причинности” в отдельности. Вместе с тем для обобщенного, комплексного исследования предпосылок, условий, контекста и обстоятельств демократического транзита и его исхода (консолидация демократии, откат в авторитаризм, неконсолидированная демократия, гибридный режим и т.п.), по-видимому, все же необходим теоретико-методологический синтез всех уровней анализа. Только тогда можно будет рассчитывать на более или менее целостное и систематизированное описание и объяснение таинственного ключевого события демократического транзита - учреждения демократического политического режима и соответствующих институтов и процедур.

Важно подчеркнуть, что методология “воронки причинности” есть лишь один из возможных путей к объяснению феномена учреждения демократии. Это, строго говоря, потенциальные методологические контуры исследования, конкретное содержательное наполнение которых применительно к каждому специфическому случаю может быть разным. Кроме того, нельзя забывать, что искомая теоретико-методологическая модель транзита должна включать аналитический синтез структурных и процедурных факторов (“структуры и агента”) на всех стадиях политических изменений, в т.ч. и после формальной “инаугурации” учреждаемых демократических институтов.

Итак, я бы следующим образом резюмировал свое отношение к эвристическому потенциалу методологии “воронки причинности”.

Неустранимый изъян “воронки причинности” — ее векторность. Она учитывает реальную множественность причинных детерминаций, но делает это как бы однонаправленно. Однако реальные причинные связи очень часто бывают разнонаправленными, даже обратными. При использовании “воронки причинности” это важное методологическое обстоятельство ускользает из поля зрения.

Тем не менее данная методология представляет собой один из допустимых и эмпирически оправданных подходов к проблеме социальной причинности. При фиксируемой множественности причин (когда потенциальных причин гораздо больше, чем наблюдаемых следствий) и отсутствии сколько-нибудь развернутых рабочих гипотез полезно попытаться каким-либо образом структурировать возможные факторы влияния. Это можно сделать посредством аналитического отсечения тех факторов (потенциальных причин), которые перестают объяснять явление. “Воронка причинности” последовательно вводит новые переменные в соответствии с новыми уровнями анализа, причем делает это только после того, как эвристический потенциал переменных предшествующего аналитического уровня исчерпан. Тем самым происходит продвижение от более общих, экзогенных факторов к более частным, эндогенным. Я по-прежнему считаю, что такой подход — в т.ч. в качестве промежуточного решения дилеммы “структуры и агента” — вполне продуктивен. Однако он всегда останется синтезом промежуточным (структурирующим и систематизирующим, но не объясняющим и не прогнозирующим), за которым рано или поздно должна 
последовать разработка интегративной теории. Если угодно, он подобен известной в аналитической философии “лестнице Витгенштейна”, которая должна быть отброшена после достижения с ее помощью определенного уровня знания.

Гельман В.Я. 2001. Постсоветские политические трансформации (Наброски к теории). — “Полис”, № 1. Капустин Б.Г. 2001. Конец транзитологии? - “Полис”, № 4.

Мельвиль А.Ю. 1998. Опыт теоретико-методологического синтеза структурного и процедурного подходов к демократическим транзитам. - Полис, № 2.

Мельвиль А.Ю. 1999. Демократические транзиты. Теоретико-методологические и прикладные аспекты. М. Almond G., Verba S. 1963. The Civic Culture: Political Attitudes and Democracy in Five Nations. Princeton. Archer M. 1990. Human Agency and Social Structure: A Critique of Giddens. — Clark J., Modhil C., Modhil S. (eds.). Anthony Giddens: Consensus and Controversy. L.

Campbell A., Converse Ph., Miller W., Stokes D. 1960. The American Voter. N.Y.

Di Palma G. 1990. To Craft Democracies. Reflections on Democratic Transitions and Beyond. Berkely. Giddens A. 1984. The Constitution of Society: Outline of a Theory of Structuration. Cambridge.

Hay C. 1995. Structure and Agency. — Marsh D., Stoker G.(eds.). Theory and Method in Political Science. Basingstoke.

Inglehart R. 1977. The Silent Revolution: Changing Values and Political Styles Among Western Publics. Princeton. Karl T., Shmitter Ph. 1991. Modes of Transition in Latin America, Southern and Eastern Europe. — International Social Science Journal, № 43.

Larsen S. (ed.) 2000. The Challenges of Theories of Democracy: Elaborations Over Trends in Transitology. Boulder, N.Y.

Linz J., Stepan A. 1996. Problems of Democratic Transition and Consolidation. Southern Europe, South America and Post-Communist Europe. Baltimore, L.

Lipset S. 1959. Some Social Requisites of Democracy: Economic Development and Political Legitimacy. American Political Science Review, № 53.

Mahony J., Snyder R. 1995. Rethinking Agency and Structure in the Study of Regime Change. Unpublished manuscript.

O’Donnell G., Shmitter Ph., Whitehead L. (eds.) 1986. Transitions from Authoritarian Rule: Comparative Perspectives. Baltimore.

Przeworski A. 1991. Democracy and the Market. Political and Economic Reforms in Eastern Europe and Latin America. Cambridge.

Pye L. 1966. Aspects of Political Development. Boston.

Rustow D. 1970. Transitions to Democracy. — Comparative Politics, № 2.

Wendt A. 1987. The Agent-Structure Problem in International Relations. — International Organization, № 41. 